|| ISSN(online): 2589-8698 || ISSN(print): 2589-868X || International Journal of Medical and Biomedical Studies

Available Online at www.ijmbs.info

PubMed (National Library of Medicine ID: 101738825)

Index Copernicus Value 2018: 75.71

\title{
USE OF THE CONDOM CATHETER TO CONTROL THE MASSIVE POSTPARTUM HEMORRHAGE
}

\author{
${ }^{1}$ Dr. Manju Agarwal, ${ }^{2}$ Dr. Rakhee Soni \\ ${ }^{1}$ Senior Professor and Unit Head, Department of Obstetrics and Gynaecology, Jhalawar Medical College, \\ Jhalawar, Rajasthan, India \\ ${ }^{2} \mathrm{PG}$ Resident, Department of Obstetrics and Gynaecology, Jhalawar Medical College, Jhalawar, Rajasthan, India
}

Article Info: Received 20 April 2019; Accepted 18 May. 2019

DOI: https://doi.org/10.32553/ijmbs.v3i5.246

Corresponding Author: Dr. Rakhee Soni, PG Resident, Department of Obstetrics and Gynaecology, Jhalawar Medical College, Jhalawar, Rajasthan, India

Conflict of interest: No conflict of interest.

\section{ABSTRACT:}

Background: To evaluate the efficacy of a condom as a tamponade for intrauterine pressure to stop massive postpartum hemorrhage (PPH)

Methods: This prospective study was done in the Obstetrics and Gynecology Department of Jhalawar Medical College and Hospital, Jhalawar, between June 2017 and October 2017. In this study period, total 30 cases of PPH were identified; 20 were managed medically,2 were managed using the B-Lynch procedure, and 7 were managed using the condom catheter,1 underwent hysterectomy. The condom catheter was used when PPH that occurred as a result of atonicity could not be controlled by uterotonics. Under aseptic precautions, a sterile foley's catheter fitted with a condom was introduced into the uterus. The condom was inflated with approximately 250-500 mL normal saline and kept for 24-48 hours, depending upon the initial intensity of blood loss, and gradually deflated when bleeding stopped.

Results: In all 7 cases in which the condom catheter was used, bleeding stopped within 15-20 minutes. No further intervention needed.

Conclusion: The hydrostatic condom catheter can control PPH in a very short time and effective manner. It is simple to use, cheap, and safe.

Keywords: PPH, Condom Catheter

\section{INTRODUCTION}

Incidence of Postpartum hemorrhage (PPH) in India is $2 \%$ to $4 \%$ in vaginal delivery and $6 \%$ in cesarean section with uterine atony being the cause in $50 \%$ cases. A population-based study has shown that PPH accounts for $28 \%$ of all maternal deaths in 8 developing countries.

Active management of the third stage of labor decreases uterine atony and is the mainstay of prevention of hemorrhage 4 . The rapid correction of blood loss with crystalloid and red cells is the first priority of management of PPH. Uterotonic drugs, such as oxytocin, prostadin or ergometrine, are used as prophylaxis and for controlling PPH. Each has advantages and disadvantages in terms of efficiency, availability, cost, stability, and ease of administration. Bimanual compression, uterine packing, and surgical interventions as B-Lynch suture, ${ }^{2,9}$ ligation of uterine artery, ovarian artery, and internal iliac artery, and embolization are effective methods for controlling intractable hemorrhage. Hysterectomy is of last choice, and a few patients need it to save their lives (Rouf $S$ et al, unpublished data). ${ }^{10,11,12}$

When medical treatment fails and before using the surgical intervention and possible hysterectomy, compression of the uterine sinuses and to stop bleeding via uterine packing can be used in management of PPH. Successful results have been shown by many researchers by using a foley's catheter as a tamponade. ${ }^{9,10}$ In light of these results, we used an inflated condom as a tamponade for 
control of massive PPH after failure of medical treatment. Our aim in this trial was to establish the efficacy of this inexpensive device to control massive $\mathrm{PPH}$.

\section{METHODS:-}

A prospective study was done in the Obstetrics and Gynecology Department of Jhalawar Medical College and Hospital, Jhalawar, between June 2017 and October 2017. Data were collected continuously from patients in 2 obstetric units. The study was approved by an institutional review board, which was constituted by the head of the department and other professors of the department. Informed consent was obtained from the patient or from her attendant if the patient's condition was poor.

\section{CHARACTERISTICS OF PATIENTS SELECTED FOR CONDOM CATHETER INTERVENTION}

Table 1: Characteristics of patients selected for condom catheter intervention

\begin{tabular}{|l|l|l|}
\hline CHARACTERISTICS & MEAN & SD \\
\hline Age (yrs) & 26.82 & 6.36 \\
\hline Parity & Range 1-6 & Median 2 \\
\hline
\end{tabular}

\begin{tabular}{|l|l|l|}
\hline MODE OF DELIVERY & NUMBER & PERCENTAGE \\
\hline Spontaneous vaginal delivery & 5 & 71.42 \\
\hline Destructive and instrumental & 1 & 14.28 \\
\hline $\begin{array}{l}\text { Lower segment cesarean } \\
\text { section }\end{array}$ & 1 & 14.28 \\
\hline Type of PPH & & \\
\hline Primary & 5 & 71.42 \\
\hline Secondary & 2 & 28.58 \\
\hline Place of Occurrence & & \\
\hline At hospital & 6 & 85.71 \\
\hline Outside hospital & 1 & 14.28 \\
\hline Interval of Delivery and PPH & & \\
\hline Immediate & 4 & 57.14 \\
\hline $1-24$ hrs & 1 & 14.28 \\
\hline 72 hrs & 2 & 28.57 \\
\hline
\end{tabular}

PREDISPOSING FACTORS FOR PPH:

Table 2: Predisposing factors for PPH

\begin{tabular}{|l|l|l|}
\hline FACTORS & NUMBER & PERCENTAGE \\
\hline Hypertension & 8 & 26.66 \\
\hline Abruptio placenta & 2 & 6.66 \\
\hline lud with fibroid & 1 & 3.33 \\
\hline Previous cesarean section & 3 & 10 \\
\hline Placenta previa & 2 & 6.66 \\
\hline Hepatitis & 5 & 16.66 \\
\hline Multiple pregnancy & 2 & 6.66 \\
\hline Morbid adhesion & 1 & 3.33 \\
\hline Prolonged labour & 4 & 13.33 \\
\hline None & 2 & 6.66 \\
\hline Total & 30 & 100 \\
\hline
\end{tabular}

\section{INTERVENTION:}

Under all aseptic precautions, a sterile foley's catheter fitted with a condom was introduced into the uterus. The condom was inflated with 250-500 $\mathrm{mL}$ normal saline according to need. Vaginal bleeding was observed and further inflation was stopped when bleeding stopped. To keep the balloon in situ, the vaginal cavity was filled with roller gauze and finally a sanitary pad. If bleeding continues, this vaginal pack will usually become soaked with blood, and if profuse it will trickle through the introitus to soak the outside pad and undergarments. This did not happen in any of our cases. Uterine tonicity was maintained by oxytocin drip for at least 6 hours after the procedure. As mentioned, the condom catheter was used in those cases in which oxytocin and other drugs were not effective for management of PPH. However, as it maintains the tone of uterus, oxytocin was simultaneously administered along with introduction of the condom catheter Antibiotics were also administered prophylactically because of the presence of a foreign body inside the uterus. The triple antibiotic regimen was administered intravenously for 7 days. High vaginal culture swab was done to determine whether there was any invading organism even after giving antibiotics. The condom catheter was kept for 24-48 hours, depending upon the initial intensity of blood loss

(Table 3). For those who had severe bleeding, the catheter was kept for the longer duration. Bleeding did not reoccur in any patient, and the condom was deflated slowly over 10 to 15 minutes after 24-48 hours.

\section{MANAGEMENT OF PATIENTS:-}

Table 3: Management of Patients

\begin{tabular}{|l|l|l|}
\hline MANAGEMENT & NUMBER & PERCENTAGE \\
\hline Introduction of condom & & \\
\hline $0-4 \mathrm{hrs}$ & 4 & 57.14 \\
\hline $5-24 \mathrm{hrs}$ & 1 & 14.28 \\
\hline $25-48 \mathrm{hrs}$ & 2 & 28.57 \\
\hline Condom kept for & & \\
\hline $24 \mathrm{hrs}$ & 5 & 71.14 \\
\hline $36 \mathrm{hrs}$ & 1 & 14.28 \\
\hline $48 \mathrm{hrs}$ & 1 & 14.28 \\
\hline Time required to control PPH & & \\
\hline $0-20$ min & 7 & \\
\hline $\begin{array}{l}\text { Saline needed to inflate the } \\
\text { balloon (ml) }\end{array}$ & 336.36 & 89.42 \\
\hline Blood transfusion needed (units) & 3.23 & 2.08 \\
\hline
\end{tabular}




\section{Main Outcome Measures}

The main outcomes evaluated in this study were the ability of the condom catheter to stop bleeding and the time required to stop bleeding after the tamponade was used.

\section{RESULT:}

After failure to control bleeding by medical measures or surgical intervention, the condom catheter was introduced. In most of the cases (57.14\%), the condom catheter was introduced within 0-4 hours, and in $34.78 \%$ of cases, between 5 and 24 hours after delivery and in $28.57 \%$ cases, between $25-48 \mathrm{hrs}$. In all 7 patients, bleeding was stopped within 15-20 minutes. The patients were followed up for 48-72 hours. Further intervention was not needed in any patient. From $200-500 \mathrm{~mL}$ (average $336.4 \mathrm{~mL}$ ) saline was required to inflate the balloon. The volume was increased until there was resistance to addition of more fluid and the bleeding ceased. On average, 3.23 units of blood (range 2-10 units) were needed to produce hemodynamic stability.

\section{DISCUSSION:}

$\mathrm{PPH}$ is the most challenging problem encountered by obstetrician study. Although most cases can be treated successfully with conservative measures, such as medication, about $10 \%$ of the women with PPH require major surgical procedures and even hysterectomy to save their lives (Rouf $S$ et al, unpublished data).

When medical intervention fails, Surgical methods are used, including uterine artery ligation, ovarian artery ligation, internal iliac artery ligation, and BLynch Brace suture. ${ }^{9,15,16}$ Each method has benefits and risks. In many cases, the above-mentioned surgical procedures are effective in avoiding hysterectomy, but delay in carrying out the procedure in some cases carries a poorer prognosis ${ }^{16}$ and each of the above methods requires a laparotomy, and there is a risk of ligature of external iliac vessels, ureteric injury, and further hemorrhage. Also skilled personnels are required to carry out these methods.

B-Lynch sutures ${ }^{2,9}$ are helpful during cesarean section, but requires a laparotomy and therefore is not method of choice in cases of PPH followed by vaginal delivery.

The advantage of uterine packing, however, is that it does not require further invasive surgery. Although there is a chance of intrauterine infection, good packing techniques with prophylactic antibiotic therapy can minimize this complication. ${ }^{18}$

A good packing technique requires careful layering of the ribbon gauze pack to occlude the whole space of the uterine cavity. Keeping the mode of action of the packing in mind, the Sengstaken-Blakemore tube and the Rusch urologic hydrostatic balloon catheter have been used by some researchers ${ }^{13,14}$ to control intractable hemorrhage. The Sengstaken-Blakemore tube is difficult to use and expensive. The Rusch urologic hydrostatic balloon catheter, although simple and effective, is also expensive and not available in our country. On the contrary, the price of a condom and foley's catheter is very low and are readily available.

The condom was used to create a tamponade function by inflation with a sufficient amount of fluid. This balloon compresses uterine sinuses in same manner as other balloons compresses the open sinuses of the uterus and stops bleeding. It is easy to use, and is easy to remove, quick and cheap. Simultaneously it has lower infection risk as there is no direct intrauterine manipulation.

Although the sample size in this study is small, we have shown that in every case, massive bleeding was controlled very quickly by inserting and inflating the condom. No patient required further intervention, and there was no serious morbidity.

In India where the maternal mortality rate from PPH is very high, this safe, cheap, and easy method can be used to save a life and to prevent the hysterectomy in young patients to conserve reproductive capacity. As condom catheter method is easy and safe, primary health workers and other healthcare providers can be trained to use this method before referring the patients to a higher center. This intrauterine tamponade method will minimize the blood loss until the patient's arrival to the hospital, which will protect the patient from irreversible shock and even death.

\section{REFERENCES:}

1. Hayman RG, Arulkumaran S, Steer PJ. Uterine compression sutures: surgical management of postpartum haemorrhage. Obstet Gynaecol. 2002; 99:502-506.

2. Vangsgaard K. "B-Lynch-suture" in uterine atony. UgeshrLaeger. 2000; 162:3468.

3. Maine $D$, Rosenfield $A$, Wallis $M$, et al. Prevention of maternal death in developing countries. New York, NY: The Center for Population of Family Health; 1999.

4. BIRPERHT. Bangladesh Institute of Research for Promotion of Essential and Reproductive Health and Technologies. 
Report on Baseline Survey for Assessment of EOC Services in Bangladesh; 1995.

5. Prendiville WJ, Elbourne D, McDonald S. Active vs expectant management of the third stage of labour (Cochrane Review). In: The Cochrane Library. Issue 3, 2000. Oxford: Update software.

6. O'Brien P, El-Refaey H, Gordon A, Geary M, Rodeck C. Rectally administered misoprostol for the treatment of postpartum haemorrhage unresponsive to oxytocine and ergometrine: a descriptive study. Obstet Gynaecol. 1998; 92:212-214.

7. Ramsey PS, Ramin KD. Rectally administered misoprostol for the treatment of postpartum haemorrhage unresponsive to oxytocine and ergometrine: a descriptive study. ObstetGynaecol. 1999; 93:157-158.

8. Abdel-Aleem H, El-Nashar I, Abdel-Aleem A. Management of severe postpartum haemorrhage with misoprostol. Int J Gynaecol Obstet. 2001; 72:75-76.

9. B-Lynch C, Coker A, Lawal AH, Abu J, Cowen MJ. The BLynch surgical technique for the control of massive postpartum haemorrhage: an alternative to hysterectomy? Five cases reported. Br J Obstet Gynaecol. 1997; 104:372375.
10. Stanco LM, Schrimmer DB, Paul RH, Mishell DR. Emergency peripartum hysterectomy and associated risk factors. Am J Obstet Gynaecol. 1993; 168:879-883.

11. Zelop CM, Harlow BL, Frigoletto FD, Safon LE, Saltzman DH. Emergency peripartum hysterectomy. Am J Obstet Gynaecol. 1993; 168:1443-1448.

12. Abu-Heija AT, Jallad FF. Emergency peripartum hysterectomy at the Princess Badees Teaching Hospital in North Jordan. J Obstet Gynaecol Res. 1999; 25:193-195.

13. Katesmark M, Brown R, Raju KS. Successful use of a Sengstaken-Blakemore tube to control massive postpartum haemorrhage. Br. J Obstet Gynaecol. 1994; 101:259-260.

14. Johanson RB, Kumar $M$, Obhrai $M$, Young $P$. Management of massive postpartum haemorrhage: use of a hydrostatic balloon catheter to avoid laparotomy. Br J ObstetGynaecol. 2001; 108:420-422.

15. O'Leary JA. Stop of haemorrhage with uterine artery ligation. Contemp Obstet Gynaecol. 1986; 28:13-16.

16. Burchell RC. Physiology of internal artery ligation. J ObstetGynaecol Br Comnwlth. 1968; 75:642-651.

17. Ramsbotham PH. Principles and Practice of Obstetrical Medicine and Surgery. Philadelphia, Pa: Blanchard and Lea; 1856; 415-416.

18. Maier RC. Control of postpartum haemorrhage with uterine packing. Am J Obstet Gynaecol. 1993; 169:317-323. 